Article

\title{
Are Hospital Chaplains Under Stress in Hong Kong? Preliminary Results from a Pilot Study
}

\author{
Leung Andrew Luk
}

Nethersole Institute of Continuing Holistic Health Education, Alice Ho Miu Ling Nethersole Charity Foundation, Hong Kong, China; aluk@nethersole.org.hk

Received: 7 May 2019; Accepted: 11 May 2019; Published: 15 May 2019

\begin{abstract}
In Hong Kong, healthcare professionals are under great stress when performing their duties in public hospitals, in which patient beds are usually fully occupied, and the workload is high. Hospital chaplains are members of the healthcare team in a hospital, as well: Are they also under stress? Furthermore, is there any relationship between religious experience and stress? This study aims to provide some background information about the health status of hospital chaplains, and to explore any relationships between stress and their spiritual experiences. A total of 100 hospital chaplains were invited to participate in this cross-sectional study, and a 60\% valid response rate was obtained. Participants completed the Depression, Anxiety and Stress Scale 21 and the Daily Spiritual Experience Scale. The results showed that most of the hospital chaplains $(78.3 \%)$ have a normal stress level, and the prevalence of mild to severe symptoms of stress is low (21.7\%) when compared with the stress levels of nurses (41.1\%) found in another study. However, more anxiety was expressed by younger hospital chaplains; this is common in caring professions, and they should have mentoring and support. All hospital chaplains have a higher level of spiritual experiences, which was not found to be related to stress.
\end{abstract}

Keywords: stress; spiritual experiences; hospital chaplains; prevalence

\section{Introduction}

The healthcare industry is one of the high-risk entities worldwide because of its high volume of users, the complexity of procedures, and the involvement of its many stakeholders. Overseas studies have shown that healthcare professionals are under great stress, and are prone to burnout, despite engaging in an incredibly meaningful and personally fulfilling job (Golbasi et al. 2008; Shanafelt et al. 2012). In Hong Kong, healthcare professionals are also under great stress when performing their duties in public hospitals, in which patient beds are usually fully occupied and the workload is high, particularly if they are unprepared to face crises at work (Siu et al. 2012; Cheung and Yip 2015). The chaplain is a member of the healthcare team in the hospitals in Hong Kong: Are they also under stress from taking care of their clients, including patients and relatives, and from supporting hospital staff?

Hong Kong is a metropolitan city with more than seven million people living in a rather small area. The hospital services are mainly provided by the public sector, which is the case for $80 \%(42)$ of the 53 hospitals (Hong Kong Government 2016). Nearly all chaplaincy services in the hospitals of Hong Kong are provided by a Christian faith-based clergy. They have been educated as clergy with additional training in clinical pastoral education (CPE). At present, there are around 150 full-time and volunteer chaplains providing chaplaincy services in hospitals (Lo 2015, p. 128). They are paid staff under the management of their respective hospital chaplaincy committee, formed by local Christian churches. In public hospitals, they are offered an honorary appointment. Since most of the hospital 
chaplains are Christian faith-based clergy, what are their religious/spiritual experiences? Is there any relation between stress and their religious experiences?

A literature review by Hsieh and Lin (2013) revealed that few studies were related to the health status of religious professionals, especially in eastern societies. With limited evidence, they concluded that religious professionals had significantly lower mortality rates than the general population. They summarized two possible underlying mechanisms. The passive mechanisms that promote health may include lifestyles that are shaped by religious commitments, such as regular life and activity schedules, better sleep quality due to a peaceful mind, and healthy behaviors (such as not smoking or drinking, having a higher internal locus of control). Active mechanisms associated with religious beliefs can foster positive psychology, social supports and quality of life, even in facing illness or disability. Although religious professionals may be healthier, they do face a number of stresses. Rowatt (2001) identified the stressors of clergy and their spouses, and grouped them into four classes: Vocational, intrapersonal, family, and social stressors. The job of a chaplain is diverse, and includes different roles, such as preacher, deliverer of rituals and sacraments, pastor, teacher, organizer, and administrator (Adams et al. 2016). Some roles may change throughout the day, and may result in a potential role overload, which also creates stress (DeShon 2012). One study by Foss (2002) showed that compared with other faith-based helping professionals, namely, counselors, teachers, nurses, and other healthcare workers, clergy had a higher level of stressors from (a) role ambiguity, (b) role conflict, (c) role overload, (d) boundary violations, (e) emotional triangulation, (f) emotional isolation, (g) exposure to crises, (h) interpersonal attack, (i) parishioners' need for help, and (j) administrative demands. In another study that compared the burnout of clergy with that of other helping professions, it was found that clergy scores were relatively better than those of police and emergency personnel, similar to those of social workers and teachers, and worse than those of counselors. Despite the numerous stressors associated with clergy, the study found that clergy exhibited moderate levels of burnout and generally coped well, and it was suggested that clergy be the models of some further study (Adams et al. 2016). Does this apply to the hospital chaplain, who is educated to be clergy, with additional training to work in hospitals to care for the sick and support the healthcare staff?

With reference to the World Health Organization ICD-10-AM "Pastoral Intervention Codings", a hospital chaplain has to perform several roles: (1) Pastoral assessment of a person's spiritual well-being and needs; (2) pastoral ministry/support to those confronted with the profound humanity issues of death and dying, loss, meaning, and aloneness, predominantly acting as a ministry of presence and support; (3) pastoral counseling or education, which may include emotional/spiritual counsel and crisis care; (4) pastoral ritual/worship, including informal prayer and rituals for individual and small groups (WHO 2002). All of these functions are no less than the roles performed by the clergy in the church, but are they under as much stress as has been indicated by the studies on clergy or healthcare professionals working in hospitals?

In the west, there is a growing study investigating chaplaincy services (Galek et al. 2011). A recent review showed that there is evidence demonstrating a relationship between chaplaincy services and increased patient satisfaction. However, limited evidence was found on the outcomes of chaplain interventions (Pesut et al. 2016). In Hong Kong, since the start of chaplaincy services in public hospitals in 1984 (Lo 2015), the emphasis has been more on clinical practice than research. However, there have been some small-scale studies conducted by a Christian organization. A quasi-experimental study was conducted by Tang (2007) with 60 patients in the experimental group who received chaplaincy care, and 57 patients in a control group without it in a public hospital with chaplaincy service provision. The results showed that patients who received chaplaincy care had higher satisfaction than those without. Furthermore, clinical pastoral care was shown to be effective in empowering patients' spiritual well-being and facilitating disease adjustment. A recent qualitative study by Luk (2017) on healthcare professionals facing work difficulties, found that hospital chaplains on night calls also encountered difficulties in terms of stress and adaptation, and felt emotional burdens from supporting the sick. 
The relation between hospital chaplains' health and religious experiences does not appear to have been studied, as no research in this area was found.

Many studies have shown that there is a relation between religion and health (Mueller et al. 2001; Koenig 2014). A person with religious beliefs may have better health, and religion is a protective factor against stress (Luk and Shek 2008; Aldwin and Park 2014). Since emerging evidence has suggested a positive association between religion/spirituality and better health, different tools have been developed to measure the component of religiousness and spirituality (Fetzer Institute 2003). Daily Spiritual Experiences refers to the emotional perception of an individual toward the transcendence in daily life (Hood et al. 1995). A Daily Spiritual Experiences Scale (DSES) was developed by Underwood and Teresi (2002), and it focuses on direct individual transcendent encounters by measuring an individual's routine experiences, rather than assessing the religion-specific beliefs or behaviors of an individual. The scale was shown to have good reliability and validity and has been used in over 70 published studies (Underwood 2011). A study of healthy lifestyle behaviors in adults by Boswell et al. (2006) revealed that daily spiritual experiences, physical activity, and a healthy diet all contributed to better physical well-being in a stress deterrent model, and these favors were deemed to counterbalance stress. In another study by Holland and Neimeyer (2005), it was found that daily spiritual experiences mitigated physical, cognitive, and emotional forms of burnout for medical and mental health practitioners working in palliative care.

A chaplain working in hospitals in Hong Kong is a clergy who has received training in his/her own religions and additional clinical pastoral education. What are their religious experiences? Since they are also members of the healthcare team in a hospital, are they also under stress? Furthermore, is there any relationship between religious experience and stress? Since there is a lack of research on hospital chaplains in Hong Kong, this study aims to provide some background information about the health status of hospital chaplains and explore any relationship between stress and their spiritual experiences. Three research questions are (1) Are hospital chaplains under stress? (2) What are the spiritual experiences of hospital chaplains? (3) Is there any relationship between stress and spiritual experience of hospital chaplains?

\section{Method}

This study used a cross-sectional descriptive design and employed a survey questionnaire to solicit responses from all hospital chaplains registered in the Association of Hong Kong Hospital Christian Chaplaincy Ministry (AHKHCCM), which is a Christian parachurch for the promotion and coordination of hospital chaplaincy services in Hong Kong. They also offer clinical pastoral education to local clergy to prepare them for working in hospitals.

The AHKHCCM is the only association for the accreditation of hospital chaplain in Hong Kong and many hospital chaplains have registered as a member. It has a member list of 100 registered hospital chaplains, occupying approximately two third of the total population of hospital chaplains in Hong Kong. A mass invitation email with a hyperlink and a PDF file of the questionnaire was delivered to all registered members two times within June to August 2018. Members were encouraged to participate in the study since the results of the study would also be used as a source of training material in a research training session in September 2018 conducted by the author. Participants either sent back questionnaires via fax or email or did it online. Anonymity and voluntary participation were ensured.

From a total number of 100 surveys sent to the chaplains in the registered list of the AHKHCCM, 61 questionnaires were returned. One was missing demographic data and excluded. Therefore, the valid return rate was $60 \%$.

The questionnaire was made up of three parts. The first part adopted the Depression Anxiety Stress Scale 21 (DASS21) consisting of 21 items in three domains. Each domain comprises seven items assessing three dimensions of mental health symptoms: depression, anxiety, and stress. The scale starts from 0 (did not apply) to 3 (most of the time). The more severe the symptoms in each dimension, 
the higher the subscale score. This instrument has well- established validity and reliability (Lovibond and Lovibond 1995). In this study, the Chinese validated translation of the DASS21 was used. Scores from each dimension were summed up and categorized as "normal", "mild", "moderate", "severe", and "extremely severe" according to the DASS manual (Lovibond and Lovibond 1995). Participants with a cut-off score of $\geq 10$ in depression, $\geq 8$ in anxiety, and $\geq 15$ in stress were considered to have these disorders, as referenced in the DASS manual (Lovibond and Lovibond 1995).

The second part of the questionnaire adopted the Daily Spiritual Experience Scale (DSES). The DSES is a 16-item self-report measure designed to assess an ordinary experience of connection with the transcendent in daily life. It includes constructs such as awe, gratitude, mercy, sense of connection with the transcendent, and compassionate love. It also measures awareness of discernment/inspiration and a sense of deep inner peace. The scale score for items 1-15 uses a six-point scale from "never" to "many times", while the last item is scored on a 4-point scale from "not close" to "as close as possible", so the total score ranges from minimum of 16 to maximum of 96 , and a higher score indicates a higher level of daily spiritual experience. This tool has well-established validity and reliability (Underwood 2011). In this study, the Chinese version (DSES- C16) was used with a Cronbach's alpha of 0.97. The mean score in a Chinese population was 49.9, S.D. $=16.5(\mathrm{Ng}$ et al. 2009). The last part of the questionnaire was self-developed to collect sociodemographic information.

\section{Results}

Participants were mostly female, accounting for 75\% (45) of the respondents. Ages ranged from 30 to over 60 , with the greatest percentage $(65 \%, n=39)$ in the age range of 51-60. The length of experience of most respondents was less than 5 years $(33.3 \%, n=20)$ and $5-10$ years $(31.7 \%, n=19)$. Many of them had acquired 4 units of CPE $(38.3 \%, n=23)$. Most were working in acute hospitals $(43.3 \%, n=26)$. The details can be seen in Table 1 .

Table 1. Background Information.

\begin{tabular}{cccc}
\hline Demographic Characteristics & $(\boldsymbol{n}=\mathbf{6 0 )}$ & Frequency & Percentage (\%) \\
\hline \multirow{3}{*}{ Gender } & Male & 14 & 23.3 \\
& Female & 45 & 75.0 \\
& Missing & 1 & 1.7 \\
Age & $31-40$ & 3 & 5.0 \\
& $41-50$ & 13 & 21.7 \\
& $51-60$ & 39 & 65.0 \\
& $>60$ & 5 & 8.3 \\
Experience & $<5$ & 20 & 33.3 \\
& $5-10$ & 19 & 31.7 \\
& $11-15$ & 9 & 15.0 \\
& $16-20$ & 3 & 5.0 \\
& $>20$ & 9 & 15.0 \\
\hline \multirow{2}{*}{ CPE Training } & 1 unit & 7 & 11.7 \\
& 2 units & 6 & 10.0 \\
& 3 units & 17 & 28.3 \\
& 4 units & 23 & 38.3 \\
& $>4$ units & 7 & 11.7 \\
\hline \multirow{2}{*}{ Workplace } & Acute hospital & 26 & 43.3 \\
& Rehabilitation hospital & 14 & 23.3 \\
& Nursing home & 1 & 1.7 \\
& Others & 19 & 31.7 \\
\hline
\end{tabular}

With cut-off scores of $\geq 10$ in depression, $\geq 8$ in anxiety, and $\geq 15$ in stress indicative of the respondent having these disorders, the prevalence of depression, anxiety, and symptoms of stress amounted to 
$16.7 \%, 31.6 \%$, and $21.7 \%$, respectively (see Table 2). No statistically significant differences were found in the demographic data of gender, years of experience, CPE training, and workplace. Age showed a statistically significant difference for the Anxiety scale, for which the 51-60 age group had better scores than those in the 41-50 and 31-40 age groups (See Table 3).

Table 2. Frequency of Depression, Anxiety, and Stress $(n=60)$.

\begin{tabular}{ccccccc}
\hline & Depression & $n \mathbf{( \% )}$ & Anxiety & $n \mathbf{( \% )}$ & Stress & $n \mathbf{( \% )}$ \\
\hline Normal & $0-9$ & $50(83.3)$ & $0-7$ & $41(68.3)$ & $0-14$ & $47(78.3)$ \\
Mild & $10-13$ & $8(13.3)$ & $8-9$ & $5(8.3)$ & $15-18$ & $8(13.3)$ \\
Moderate & $14-20$ & $2(3.4)$ & $10-14$ & $9(15.0)$ & $19-25$ & $4(6.7)$ \\
Severe & $21-27$ & - & $15-19$ & $5(8.3)$ & $26-33$ & $1(1.7)$ \\
Extremely & $28+$ & - & $20+$ & - & $34+$ & - \\
Severe & & & & & & \\
\hline
\end{tabular}

Table 3. One-way analysis of variance of Anxiety by Age $(n=60)$.

\begin{tabular}{cccccccc}
\hline & $\begin{array}{c}\text { Age } \\
\text { Groups }\end{array}$ & $\boldsymbol{n}$ & $\begin{array}{c}\text { Anxiety } \\
\text { Mean }\end{array}$ & SD & F & Sig. & $\begin{array}{c}\text { Post Hoc } \\
\text { LSD }\end{array}$ \\
\hline 1. & $31-40$ & 3 & 12.0 & 2.0 & 3.287 & 0.02 & $3<2<1$ \\
2. & $41-50$ & 13 & 7.7 & 5.5 & & & \\
3. & $51-60$ & 39 & 4.7 & 4.4 & & \\
4. & $>60$ & 5 & 5.6 & 5.2 & & \\
\hline
\end{tabular}

Most of the scores on the DSES were concentrated in the upper range of the total score, with the highest percentage of 51\% (31) scoring in the range of 69-81 (See Table 4). The mean score was 71.8, $\mathrm{SD}=9.7$. No statistically significant differences were found in any of the demographic data, including gender, age, experience, CPE education, and workplace.

Table 4. Frequency of Distribution of DSES $(n=60)$.

\begin{tabular}{ccc}
\hline Range of Score & Frequencies & Percentage (\%) \\
\hline $26-29$ & 0 & - \\
$30-42$ & 0 & - \\
$43-55$ & 4 & 6.7 \\
$56-68$ & 15 & 25.0 \\
$69-81$ & 31 & 51.6 \\
$82-94$ & 10 & 16.7 \\
\hline
\end{tabular}

Potential correlation of DSES with the depression, anxiety, and stress scale was analyzed, and although DSES scores were negatively correlated with stress, anxiety, and depression, no statistically significant relationships were detected. Details can be seen in Table 5.

Table 5. Correlation of Depression, Anxiety, Stress with DSES.

\begin{tabular}{ccc}
\hline & & DSES \\
\hline \multirow{3}{*}{ Depression } & Pearson Correlation & -0.142 \\
& Sig. (2-tailed) & 0.278 \\
& $n$ & 60 \\
\hline \multirow{3}{*}{ Anxiety } & Pearson Correlation & -0.238 \\
& Sig. (2-tailed) & 0.067 \\
& $n$ & 60 \\
\hline \multirow{2}{*}{ Stress } & Pearson Correlation & -0.214 \\
& Sig. (2-tailed) & 0.100 \\
& $n$ & 60 \\
\hline
\end{tabular}




\section{Discussion}

The sociodemographic characteristics of gender, experience, and CPE training among the respondents in the sample are very similar to those of the population of registered hospital chaplains, with differences ranging from 0 to 7 percent in each subcategory between the sample population and data from the annual report of the association. For example, the proportion of male to female registered hospital chaplains in the association is $27 \%$ (27) and $73 \%$ (73), respectively (Association of Hong Kong Hospital Christian Chaplaincy Ministry 2017, p. 17). The sample size can be considered representative of the population of the registered hospital chaplains, however, it cannot be represented for the whole population of hospital chaplains in Hong Kong since approximate one third of them are not members of the association. This study is a pilot study and caution needs to be taken when interpreting the results.

Compared with a study of nurses in Hong Kong that revealed a prevalence of depression, anxiety, and stress of $35.8 \%, 37.3 \%$, and $41.1 \%$, respectively (Cheung and Yip 2015), the present study shows that hospital chaplains have a much lower prevalence. Similarly, the prevalence rates of anxiety and depression among hospital chaplains are lower than the prevalence rates of depression $(40.2 \%)$ among caregivers of stroke patients (Loh et al. 2016), as well as the prevalence rates of depression (34\%) and anxiety (43.6\%) among caregivers of dementia patients (Sallim et al. 2015). Nurses and caregivers need to look after the patients most of the time, and they may not have religious support. As a result, nurses and caregivers report a higher prevalence of depression and anxiety as compared with hospital chaplains.

A further comparison of depression and stress between this study's population and nurses who are members of a hospital healthcare team indicates that the proportion of hospital chaplains suffering from depression and symptoms of stress is less than half of that of nurses. However, the proportion of anxiety is closer between the two groups, and this reflects that both are coping with anxiety in their work. There are some possible reasons that nurses are more stressful than hospital chaplains. Firstly, part of a nurse's job is related to patients' life and death, so the job is more stressful in nature. Secondly, most nurses have to work in shifts, and shift work affects sleeping patterns and daily life. Nurses need more adaptation to their work circumstances. A local study by Chan (2009) investigating the impact of shift work rotation on Hong Kong nurses concluded that $70 \%(n=163)$ of the respondents suffered from poor sleep. Lastly, people in the general public have higher expectations of nurses. Moreover, they receive more complaints and even face lawsuits if an error occurs during their delivery of duties, thus creating more stress.

Age is found to significantly correlate with anxiety. In this sample, as age increases, anxiety symptoms decrease, except for those over 60. Of the age group, the 31-40 group had the highest mean score for anxiety. This finding is consistent with that of Cheung and Yip (2015), who showed an inverse relationship between age and anxiety. One possible explanation is that the life experiences gained with increasing age may lead to better management of stress and lower anxiety. On the other hand, the nature of both nursing and chaplaincy services involves emotional labor, and this is why both professions face anxiety, especially those who are younger. Better mentoring should be offered to those who are younger in these professions.

The DSES scoring is skewed toward the higher end, with a mean score of $71.77, \mathrm{SD}=9.71$. When compared with a study of 245 professional and support staff in a rehabilitation service complex in Hong Kong with a mean score of 49.9, S.D. $=16.5$ ( Ng et al. 2009), the present study shows a much higher DSES score. Furthermore, the present study does not reveal any statistically significant differences in the DSES score among the demographic groups, including gender, age, experiences, CPE training, and workplace. This finding is inconsistent with the results of a study conducted by Ng et al. in 2009 . There are several possible reasons for the discrepancy. Firstly, this study consists of a homogeneous sample of respondents, namely, hospital chaplains who are clergy, while the participants in the compared study were largely non-religious persons. Secondly, hospital chaplains with a Christian faith-based religion well believe that love is from God. Daily spiritual experience is paramount and means an encounter with God and the receipt of His strength for offering care to those in need. Hospital 
chaplains are likely to spend more time focusing on their daily spiritual experiences. As witnessed by a hospital chaplain's self-reflection, "I think, hospital chaplain as a God's spokesman to visit our patients, personal spirituality and the relation with God are mostly important, she has to reflect all the times and pray for appropriate words from God to respond to our patients" (Yeung 2018, p. 9). This may be an explanation for most of the subjects in this study having high scores in their responses and the absence of significant differences in their demographic data.

No statistically significant associations were evident between the symptoms of stress and the DSES score. One possible reason is that this study had a small number of participants who were homogeneous in nature, so their differences are not easily identified. Another reason may be that stress is a natural response to stressors or stimuli in our daily life because it is a protective mechanism in human beings. Most of our participants, among them $70 \%$ aged over 51 , score within ranges indicative of normal stress levels, which may not be related to their spiritual experiences, but to their maturity in life experiences. Lastly, there are many studies supporting other factors associated with stress which apply to general population with or without religion practices. Fornes-Vives et al. (2016) study found a highly significant correlation between emotional coping and the neuroticism trait. Coping, stress, and personality changed positively during the nursing 3 years training program. The study by Chao (2011) showed that social support appears to buffer the relationship between perceived stress and psychological well-being of college students, and the moderating effect is mediated by problem-focused coping. Another study also reveals that various physical exercises may be used to decrease one's perceived stress in moderately to highly stressed individuals (Neves et al. 2014). An older research by Callaghan et al. (2000) examines nurses' coping strategies for 500 Hong Kong nurses, finding that most seek to deal with difficulties by supports from friends and colleagues. Beyond finding spiritual comfort, engagement in other leisure activities (e.g., resting, sleeping well, relaxation) is also found useful.

\section{Limitations and Directions for Future Research}

There are some limitations of this study. First, the use of the DASS, which is a generic instrument, makes it unclear whether the depression, anxiety, or stress reported by the participants can be attributed to their work in the hospital. The DASS limits to events in the past week and participants' report may thus be subject to under/over-reporting. Second, the DSES results do not show any correlations with the DASS results, so there is no clear demonstration of any "buffering" effect of spirituality. Some other factors, such as coping styles, personality, social support, physical exercises, leisure activities should be considered together to see if there is any association in future study. Some other scales for measuring spirituality and/or religion should also be considered for further exploration. Third, the sample size is quite small, which may affect the reliability of the statistical tests. Since the total population of the hospital chaplains in Hong Kong is not great and the locality is near, it is worthwhile to conduct another survey to collect questionnaire from the whole population. Finally, this study is limited by its cross-sectional design, meaning that it cannot investigate qualitative or narrative comments concerning their services and coping mechanisms. Furthermore, quantitative data alone may not provide an adequate picture of the emotional state of hospital chaplains, and further qualitative study by means of in-depth interviews or focus groups to explore more information related to the research questions should be considered.

\section{Conclusions}

This study found that most of the hospital chaplains (78.3\%) had normal stress levels. The prevalence of mild to severe symptoms of stress was low $(21.7 \%)$ compared with the prevalence found in nurses $(41.1 \%)$ in another study. However, more anxiety was found to be expressed by the younger hospital chaplains; this is common in caring professions, and they should have mentoring and support. All hospital chaplains had a higher level of spiritual experiences. Regarding the relation of stress and spirituality, until a more comprehensive study with larger sampling and qualitative research 
can be conducted, this study has provided preliminary evidence that no significantly relation is found between them. Further research should be conducted for exploration in this area.

Funding: This research received no external funding.

Acknowledgments: Rev. Lo, W. C, Director of the Association of Hong Kong Hospital Christian Chaplaincy Ministries for his full support of the study.

Conflicts of Interest: The author declares no conflict of interest.

\section{References}

Adams, Christopher J., Hooly Hough, Rae Jean Proeschold-Bell, Jia Yao, and Melanie Kolkin. 2016. Clergy burnout: A comparison study with other helping professions. Pastoral Psychology 65: 427-568. [CrossRef]

Aldwin, Carolyn M., and Crystak L. Park. 2014. Differing pathways between religiousness, spirituality, and health: A self-regulation perspective. Psychological Religious Spirit 6: 9-21. [CrossRef]

Association of Hong Kong Hospital Christian Chaplaincy Ministry. 2017. Annual Report 2017; Hong Kong: Association of Hong Kong Hospital Christian Chaplaincy Ministry, p. 17.

Boswell, Gracie H., Eva Kahana, and Peggye Dilworth-Anderson. 2006. Spirituality and healthy lifestyle behaviors: Stress counter-balancing effects on the well-being of older adults. Journal Religious Health 45: 587-602. [CrossRef]

Callaghan, Patrick, Shiu Ann Tak-Ying, and Peggy A. Wyatt. 2000. Factors related to stress and coping among Chinese nurses in Hong Kong. Journal of Advanced Nursing 31: 1518-27. [CrossRef] [PubMed]

Chan, Moon Fai. 2009. Factors associated with perceived sleep quality of nurses working on rotating shift. Journal of Clinical Nursing 18: 285-93. [CrossRef] [PubMed]

Chao, Ruth C. L. 2011. Managing Stress and Maintaining Well-Being: Social Support, Problem-Focused Coping, and Avoidant Coping. Journal of Counseling \& Development 89: 338-48.

Cheung, Teris, and Paul Yip. 2015. Depression, anxiety and symptoms of stress among Hong Kong nurses: A cross-sectional study. International Journal of Environmental Research and Public Health 12: 11072-100. [CrossRef]

DeShon, Richard P. 2012. Clergy Effectiveness: National Survey Results Summary; General Board of Higher Education and Ministry. The United Methodist Church. Available online: http://www.gbhem.org/sites/default/files/ coucuments/bom/BOM_CleryEffectivenessSummary2012.pdf (accessed on 12 December 2018).

Fetzer Institute. 2003. Multidimensional Measurement of Religiousness, Spirituality for Use in Health Research: A Report of a National Working Group. Kalamazoo: Fetzer Institute.

Fornes-Vives, Joana, Gloria Garcia-Banda, Dolores Frias-Navarro, and Gerard Rosales-Viladrich. 2016. Coping, stress, and personality in Spanish nursing students: A longitudinal study. Nurse Education Today 36: 318-23. [CrossRef]

Foss, Richard Wayne. 2002. Burnout among clergy and helping professionals: Situational and personality correlates. Dissertation Abstracts International: Section B: The Sciences and Engineering 63: 1596.

Galek, Kathleen, Kevin J. Flannelly, Katherine RB Jankowski, and George F. Handzo. 2011. A methodological analysis of chaplaincy research: 2000-2009. Journal of Health Care Chaplaincy 17: 126-45. [CrossRef]

Golbasi, Zehra, Meral Kelleci, and Selma Dogan. 2008. Relationships between coping strategies, individual characteristics and job satisfaction in a sample of hospital nurses: Cross-sectional questionnaire survey. International Journal of Nursing Studies 45: 1800-6. [CrossRef]

Holland, Jason M., and Robert A. Neimeyer. 2005. Reducing the risk of burnout in end-of-life care settings: The role of daily spiritual experiences and training. Palliative Support Care 3: 173-81. [CrossRef]

Hong Kong Government. 2016. Hong Kong Fact Sheet: Public Health; Hong Kong: Hong Kong Special Administration Region, China.

Hood, Ralp W., Bernard Spilka, Bruce Hunsberger, and R. Gorsuch. 1995. The Psychology of Religion, 2nd ed. New York: Guilford.

Hsieh, Chih Chin, and Pay-Shin Lin. 2013. From the health status of religious professionals to understand the relationship of religion and health. Formosan Journal of Medicine 17: 207-16. (In Chinese).

Koenig, Harold G. 2014. Depression in chronic illness: does religion help? Journal of Christian Nursing 31: 40-46. [CrossRef] [PubMed] 
Lo, W. C. 2015. Spirituality and Medicine. Hong Kong: Association of Hong Kong Hospital Christian Chaplaincy Ministries, p. 128. (In Chinese)

Loh, Alvona Z., Julia S. Tan, Melvyn W. Zhang, and Roger C. Ho. 2016. The Global Prevalence of Anxiety and Depressive Symptoms Among Caregivers of Stroke Survivors. Journal of the American Medical Directors Association 18: 111-16. [CrossRef] [PubMed]

Lovibond, Peter F., and Sydney H. Lovibond. 1995. The structure of negative emotional states: Comparison of the Depression anxiety Stress Scales (DASS21) with the beck depression and anxiety inventories. Behavior Research and Therapy 33: 335-43. [CrossRef]

Luk, Andrew Leung. 2017. Holistic Care: Case Studies. Hong Kong: Nethersole Institute of Continuing Holistic Health Education, p. 145. (In Chinese)

Luk, Andrew Leung, and D. Shek. 2008. The experiences and perceived changes of Chinese ex-mental patients attending a holistic psychiatric rehabilitation programme: A qualitative study. Journal of Psychiatric and Mental Health Nursing 15: 447-57. [CrossRef]

Neves, MK Magalhaes Das, J. M. Loots, and R. L. Van Niekerk. 2014. The effect of various physical exercise modes on perceived psychological stress. South African Journal of Sports Medicine 26: 104-8. [CrossRef]

Mueller, Paul S., David J. Plevak, and Teresa A. Rummans. 2001. Religious involvement, spirituality, and medicine: Implications for clinical practice. Mayo Clinic Proceedings 76: 1225-35. [CrossRef]

Ng, Siu-Man, Ted CT Fong, Elaine YL Tsui, Friendly SW Au-Yeung, and Sally KW Law. 2009. Validation of the Chinese version of Underwood's Daily Spiritual Experience Scale-Transcending cultural boundaries? International Journal of Behavioral Medicine 16: 91-97. [CrossRef] [PubMed]

Pesut, Barbara, Shane Sinclair, George Fitchett, Madeleine Greig, and Sarah e. Koss. 2016. A scoping review of the evidence 2009-2014. Journal of Health Care Chaplaincy 22: 67-84. [CrossRef]

Rowatt, G. Wade. 2001. Stress and satisfaction in ministry families. Review and Expositor 98: 523-43. [CrossRef]

Sallim, Adnaan Bin, Andrew Arjun Sayampanathan, Amit Cuttilan, and Roger Chun-Man Ho. 2015. Prevalence of Mental Health Disorders among Caregivers of Patients with Alzheimer Disease. Journal of the American Medical Directors Association 16: 1034-41. [CrossRef] [PubMed]

Shanafelt, Tait D., Sonja Boone, Litjen Tan, Lotte N. Dyrbye, Wayne Sotile, Daniel Satele, Colin P. West, Jeff Sloan, and Michael R. Oreskovich. 2012. Burnout and satisfaction with work-life balance among US physicians relative to the general US population. Archive of International Medicine 172: 1377-85. [CrossRef]

Siu, Christina F. Y., S. K. Yuen, and Andy Cheung. 2012. Burnout among public doctors in Hong Kong: cross-sectional survey. Hong Kong Medical Journal 18: 186-92. [PubMed]

Tang, Andrew C. W. 2007. Enhancing spiritual resilience: Pathways of awakening for wellness realization in holistic care. In Spirituality, Religion \& Holistic Health: Transcendency of Human Predicament. Edited by Leung Andrew Luk. Hong Kong: Soul-mate Co., Ltd., pp. 142-62. (In Chinese)

Underwood, Lynn G. 2011. The daily spiritual experience scale: Overview and results. Religion 3: 29-50. [CrossRef]

Underwood, Lynn G., and Jeanne A. Teresi. 2002. The Daily Spiritual Experience Scale: development, theoretical description, reliability, exploratory factor analysis, and preliminary construct validity using health-related data. Annals of Behavioral Medicine 24: 22-33. [CrossRef] [PubMed]

WHO. 2002. Tabular List of Procedures ICD-10-AM: Australian Classification of Health Interventions. In The International Statistical Classification of Diseases and Related Health Problems, 10th rev. ed. Pastoral Intervention Codings. Sydney: World Health Organization and the National Centre for Classification in Health, University of Sydney, vol. 3.

Yeung, Pui Kwan. 2018. Bringing a firing heart to serve. Tender Voice Bimonthly 28: 9. (In Chinese).

(C) 2019 by the author. Licensee MDPI, Basel, Switzerland. This article is an open access article distributed under the terms and conditions of the Creative Commons Attribution (CC BY) license (http://creativecommons.org/licenses/by/4.0/). 